\title{
Contributions to the systematics of New World macro-moths VII
}

\author{
B. Christian Schmidt', J. Donald Lafontaine' \\ I Canadian National Collection of Insects, Arachnids, and Nematodes, Ottawa Research and Development \\ Centre, Agriculture and Agri-Food Canada, KW Neatby Bldg., 960 Carling Ave., Ottawa, Ontario, Canada \\ K1A OC6
}

Corresponding author: B.C. Schmidt (christian.schmidt@canada.ca), J.D. Lafontaine (Don.Lafontaine@agr.gc.ca)

Received 28 September 2018 | Accepted 28 September 2018 | Published 8 October 2018

http://zoobank.org/7D9DC509-72DB-4157-968F-B23AC3C85F41

Citation: Schmidt BC, Lafontaine JD (2018) Contributions to the systematics of New World macro-moths VII. In: Schmidt BC, Lafontaine JD (Eds) Contributions to the systematics of New World macro-moths VII. ZooKeys 788 : 1-2. https://doi.org/10.3897/zookeys.788.30148

This special issue of ZooKeys is the seventh volume in the "Contributions" series, dedicated to disseminating systematics research on the Noctuoidea, Geometroidea, and other macro-moth groups. Previous volumes were published in May 2009 (volume I, ZooKeys \# 9), March 2010 (volume II, ZooKeys \# 39), November 2011 (volume III, ZooKeys \# 149), February 2013 (volume IV, ZooKeys \# 264), June 2014 (volume V, ZooKeys \# 421) and October 2015 (volume VI, ZooKeys \# 527; see Schmidt and Lafontaine 2009, 2010, 2011, 2013, 2014, 2015). Authors interested in contributing to future "Contributions" volumes are encouraged to contact us.

In the current volume, eighteen authors contributed eleven manuscripts on New World taxa in the Erebidae, Noctuidae and Apatelodidae. In addition to numerous taxonomic and nomenclatural changes, 16 new taxa are described from the Nearctic, including 1 new genus, 14 new species and one subspecies: Hypoprepia lampyroides Palting \& Ferguson, sp. n., Clemensia ochracea Schmidt \& Sullivan, sp. n., Euchaetes nancyae Nagle \& Schmidt, sp. n., Dolocucullia poolei Crabo \& Hammond, sp. n., Sympistis eleaner Adams, sp. n., Sympistis ferrirena Crabo, sp. n., Aseptis harpi Crabo \& Mustelin, 
sp. n., Admetovis icarus Crabo \& Schmidt, sp. n., Rhabdorthodes Crabo, gen. n., Rhabdorthodes pattersoni Crabo, sp. n., R. petersoni Crabo, sp. n., Hypotrix lactomellis Wikle \& Crabo, sp. n., Plagiomimicus yakama Crabo \& Wikle, sp. n., P. yakama mojave Wikle \& Crabo, ssp. n. and Plagiomimicus incomitatus Mustelin, sp. n.

An additional eight species are described from the Neotropics: Apatelodes navarroi Herbin \& Beccacece, sp. n., Apatelodes chalupae Herbin \& Beccacece, sp. n., Apatelodes ulfi Herbin \& Beccacece, sp. n., Lophocampa azuayensis Vincent, sp. n., Lophocampa carpishensis Vincent, sp. n., Leucosigma solisae Goldstein, sp. n., Leucosigma poolei Goldstein, sp. n. and Leucosigma schausi Goldstein, sp. n.

All updates, additions and corrections to the Check List of North American Noctuoidea (Lafontaine and Schmidt 2010) since the last update in 2015 are summarized.

\section{References}

Lafontaine D, Schmidt C (2010) Annotated check list of the Noctuoidea (Insecta, Lepidoptera) of North America north of Mexico. ZooKeys 40: 1-239. https://doi.org/10.3897/ zookeys. 40.414

Schmidt C, Lafontaine D (2009) Contributions to the Systematics of New World MacroMoths. ZooKeys 9: 1-2. https://doi.org/10.3897/zookeys.9.183

Schmidt C, Lafontaine D (2010) Contributions to the systematics of New World macro-moths II. ZooKeys 39: 1-2. https://doi.org/10.3897/zookeys.39.442

Schmidt C, Lafontaine D (2011) Contributions to the systematics of New World macro-moths III. ZooKeys 149: 1-4. https://doi.org/10.3897/zookeys.149.2383

Schmidt C, Lafontaine D (2013) Contributions to the systematics of New World macro-moths IV. ZooKeys 264: 1-2. https://doi.org/10.3897/zookeys.264.4687

Schmidt BC, Lafontaine JD (2014) Contributions to the systematics of New World macromoths V. ZooKeys 421: 1-2. https://doi.org/10.3897/zookeys.421.8050

Schmidt BC, Lafontaine JD (2015) Contributions to the systematics of New World macromoths VI. In: Schmidt BC, Lafontaine JD (Eds) Contributions to the systematics of New World macro-moths VI. ZooKeys 527: 1-2. https://doi.org/10.3897/zookeys.527.6803 